\title{
ANTICORPOS INIBIDORES DA HEMAGLUTINAÇÃO PARA O VIRUS PARAINFLUENZA 3 (HA-1), EM GADO BOVINO ${ }^{(1)}$
}

José Alberto N. CANDEIAS (2)

Luiz Conrado RIBEIRO (3)

\begin{abstract}
Um inquérito sorológico feito em gado bovino proveniente de 19 Municípios do Estado de Sá Paulo, mostrou que 36,71\% dos animais observados tinham anticorpos inibidores da hemaglutinação para o virus parainfluenza 3 (HA-1), resultado que sugere a disseminaçá da infecção por este vírus no grupo de animais estudados, mesmo levando em consideração que a cêpa utilizada, como antígeno, era uma cêpa heteróloga.
\end{abstract}

\section{N T R O D U C A}

As observações feitas por Chanock et alii $^{7}$ (1958) a respeito dos vírus parainfluenza como agentes etiológicos de in. feç̧ões respiratórias em crianças, foram logo seguidas do isolamento, de bovinos com um quadro respiratório -conhecido pelo nome de "febre dos transportes", de uma cêpa de vírus parainfluenza 3 (Reisinger, Heddleston \& Manthei ${ }^{17}$, 1959). Numerosos autores demonstraram, em diversas espécies animais, a existência de infecção ocasionada pelo vírus parainfluenza 3 (CooK et alii ${ }^{10}$, 1959; Woods et alii ${ }^{22}$, 1964; Charton et alii ${ }^{3}$, 1965; Fischman ${ }^{13}, 1967$ ). Através de reações de neutralização e inibição da hemaglutinação, ABINANTI \& HUEBNER ${ }^{1}$ (1959) notaram uma semelhança antigênica entre a cêpa humana HA.l e a cêpa de origem bovina SF.4, chegando a afirmar que, em face desta semelhança, as duas cêpas pertenceriam a uma mesma espécie, com diferentes hospedeiros. No entanto, Abinanti et alii ${ }^{2}$ (1960) mostraram que estas cêpas podiam diferençar-se, mediante reações de neutralização com sôros preparados em cobaia, por inoculação intranasal. Fischman \& BANG ${ }^{12}$ (1966), valendo-se da técnica de Ouchterlony, verificaram que as relaçōes antigênicas entre as cêpas humana e bovina são do tipo "reação cruzada de identidade parcial", isto é, um sôro preparado contra a cêpa de origem bovina reage com as cêpas homóloga e heteróloga, ainda que mais fortemente com a homóloga; já o sôro preparado contra a cêpa de origem humana reage, regularmente, com a cêpa homóloga, dando resultados não uniformes com a cêpa heteróloga.

O presente trabalho, teve por finalidade verificar a extensão da presença de anticorpos inibidores da hemaglutinação, no sôro de bovinos adultos normais, utilizando-se, para tal, o antígeno de origem humana (HA-1).

Recebido para publicação em 24-9-1968.

(1) Da Cadeira de Microbiologla Aplicada da Faculdade de Higiene e Saúde Pública da USP.

(2) Da Cadeira de Microbiologia Aplicada da FHSP.

(3) Da Secção de Virus do Instituto Biológico de São Paulo. 
CANDEIAS, J. A. N. \& RIBEIRO, L. C. - Anticorpos inibidores da hemaglutinação para o vírus parainfluenża 3 (HA-1), em gado bovino. Rev. Saúde públ., S. Paulo, 2(2):180-185, dez. 1968.

MATERIAL E M TODOS

Amostras de soros - As amostras de soros utilizadas foram colhidas de bovinos adultos normais, provenientes de propriedades localizadas em diversas Municípios do Estado de São Paulo. Foram colhidas 553 amostras, sem ter assistido a esta colheita a preocupação de respeitar um plano de amostragem capaz de permitir ulterior generalização dos resultados para os animais da área escolhida. A colheita teve início em novembro de 1967, prolongando-se até março de 1968, sendo os soros congelados a $-20^{\circ} \mathrm{C}$ até o momento do exame.

Virus padrão - A cêpa humana de virus parainfluenza $3 \mathrm{HA} \cdot 1$ foi obtida do Virus Reference Laboratory - Central Public Health Laboratories, Londres $O$ antígeno para a reação foi preparado em culturas primárias de rim de macaco rhesus, mediante a inoculação de $\quad, 2 \mathrm{ml}$ da amostra padrão de vírus e $0,8 \mathrm{ml}$ de meio 199, adicionado de penicilina e estreptomicina na concentração final de $\mathbf{2 0 0}$ unidades por $\mathrm{ml}$. As culturas infectadas foram incubadas a $33^{\circ} \mathrm{C}$ até o efeito citopático máximo. A titulação, por hemadsorção, com uma suspensão de hemácias de cobaia a $0,4 \%$, após incubação, durante 20 minutos, a $4^{\circ} \mathrm{C}$, deu, regularmente, títulos de $10^{5,5} \mathrm{TCD}_{50}$. As culturas congeladas e descongeladas por três vêzes, constituiram o antígeno utilizado na reação.

Reação de inibição da hemaglutinação - Esta reação foi executada conforme o método de SEver ${ }^{19}$ (1962), com algumas modificaçóes (APHA ${ }^{4}, 1964$ ), utilizando-se o conjunto microtitulador de Takatsy (TAKATSY ${ }^{21}$ ).
Os soros foram inativados a $56^{\circ} \mathrm{C}$ durante 30 minutos, tratados com caolin a $20 \%$ e com uma suspensão de glóbulos vermelhos de cobaia a 50\%. Depois de diluídos seriadamente - fator 2 - a ca-. da $0,025 \mathrm{ml}$ da diluição do sôro foi adicionado igual volume de antígeno contendo 4 unidades hemaglutinantes, sendo as. misturas mantidas à temperatura ambiente por 60 minutos, depois do que receberam $0,025 \mathrm{ml}$ de uma suspensão a $0,8 \%$. de hemácias de cobaia. A leitura dos: resultados foi feita depois de 90 minutos, mantendo-se as misturas à temperatura ambiente. Incluiram-se na reação contrôles de sôro, hemácias e vírus. Todos os especímens positivos em diluições iguais. ou superiores a $1: 20$ foram considerados. como soros positivos.

\section{R ESULT A DOS}

Do total de 553 soros examinados, $36,71 \%$. foram positivos e $63,29 \%$ negativos (Tabela 1). Dos soros positivos,

$$
\begin{array}{llllll}
\text { T A } & \text { B } & \mathbf{E} & \mathbf{L} & \mathbf{A} & \mathbf{1}
\end{array}
$$

Número e porcentagem de soros positivos e negativos para a cêpa HA-1 de virus parainfluenza 3, no grupo de bovinos examinados

\begin{tabular}{c|c|c|c|c}
\hline $\begin{array}{c}\text { Total de } \\
\text { soros } \\
\text { examinados }\end{array}$ & \multicolumn{2}{|c|}{$\begin{array}{c}\text { Soros } \\
\text { positivos }\end{array}$} & \multicolumn{2}{|c|}{$\begin{array}{c}\text { Soros } \\
\text { negativos }\end{array}$} \\
\cline { 2 - 6 } & No & $\%$ & Ne & $\%$ \\
\hline 553 & 203 & 36,71 & 350 & 63,29 \\
\hline
\end{tabular}

$20,61 \%$ tinham título $20,13,92 \%$, título 40 e $1,99 \%$, título 80 ; só em uma amostra de sôro foi encontrado um título de 160. Nos soros considerados como negativos, a distribuição foi de $35,26 \%$ com título 10 e $28,03 \%$, com título inferior a 10 (Fig. 1). 
CANDEIAS, J. A. N. \& RIBEIRO, L. C. - Anticorpos inibidores da hemaglutinaçáo para o virus parainfluenza 3 (HA-1), em gado bovino. Rev. Saude publ., S. Paulo, z(2):180-185, dez. 1968.

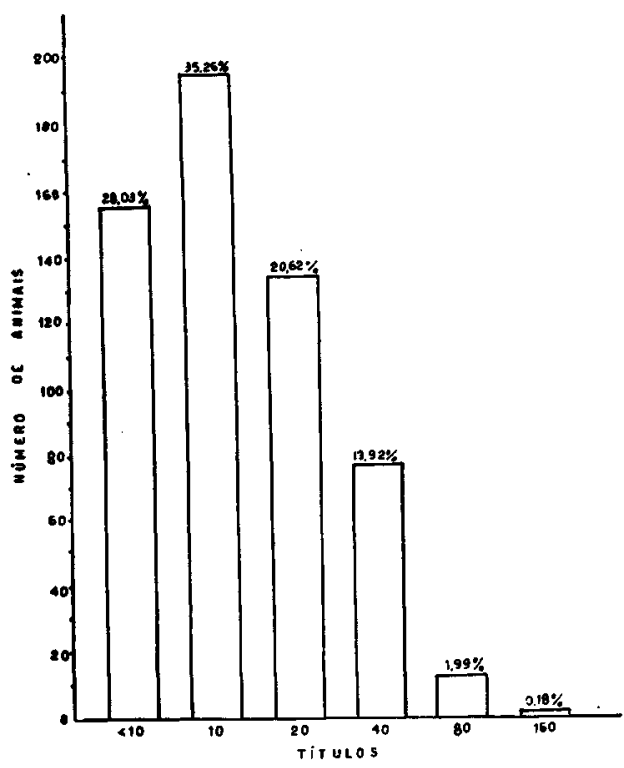

Fig. 1 - Distribuição dos títulos de anticorpos inibidores da hemaglutinaçăo para a cêpa HA-1 de vírus parainfluenza 3 , em bovinos.
$\mathrm{Na}$ Tabela 2 apresentamos a distribuição dos soros positivos segundo a localização das propriedades por Município.

\section{I S C U S A O}

A reação de inibição da hemaglutinação é de grande utilidade na pesquisa de anticorpos para o vírus parainfluenza 3 , no sôro de bovinos e outras espécies animais, não só pela facilidade de sua realização como pela boa correlação existente entre os seus resultados e os da prova de neutralização (HoERLEIN et alii ${ }^{14}$, 1959; Reisinger, Heddleston \& MaNTHEI $\left.{ }^{17}, 1959\right)$. Num estudo sorológico sôbre o vírus parainfluenza 3 , em bovinos, Abinantri et alii ${ }^{3}$ (1961) encontraram em $70 \%$ dos animais destinados a matadouros, títulos de anticorpos inibidores da hemaglutinação da ordem de 20 ou superiores, considerando-os como índice de reação positiva. Os resultados de nossa

T A B E L A 2

Distribuição dos soros positivos para a cêpa HA-1 de virus parainfluenza 3, no grupo de bovinos examinados, segundo a localizaçáo das propriedades

\begin{tabular}{|c|c|c|c|c|}
\hline & \multirow{2}{*}{$\begin{array}{c}\text { Localização } \\
\text { das } \\
\text { propriedades }\end{array}$} & \multirow{2}{*}{$\begin{array}{l}\text { Total de } \\
\text { soros } \\
\text { examinados }\end{array}$} & \multicolumn{2}{|c|}{ Soros Positivos } \\
\hline & & & $\mathbf{N}$ & $\%$ \\
\hline Municipio & Amparo & 19 & 8 & 42,10 \\
\hline$"$ & Araras & 30 & 14 & 46,67 \\
\hline$"$ & Braganca & 50 & 20 & 40,00 \\
\hline$"$ & Campinas & 25 & 12 & 48,00 \\
\hline$"$ & Campo Limpo & 25 & 5 & 20,00 \\
\hline$"$ & Casa Branca & 14 & 4 & $\mathbf{2 8 , 5 7}$ \\
\hline$"$ & Cotia & 26 & 9 & 34,61 \\
\hline$"$ & Itapetininga & 48 & 23 & 47,91 \\
\hline$"$ & Jarinu & 32 & 13 & 40,62 \\
\hline & Jaú & 23 & 6 & 26,08 \\
\hline$"$ & Jundiai & 32 & 12 & 37,50 \\
\hline " & Juquiáa & 28 & 10 & 35,71 \\
\hline$"$ & Miracatú & 30 & 10 & $\mathbf{3 3}, \mathbf{3 3}$ \\
\hline$"$ & Nova Odessa & 22 & 10 & 45,45 \\
\hline$"$ & Pedreira & 50 & 18 & 36,00 \\
\hline$"$ & Pirassununga & 28 & 11 & 39,28 \\
\hline$"$ & Santa Rita & 20 & 6 & 30,00 \\
\hline & São Carlos & 21 & 4 & 19,04 \\
\hline$n$ & São Paulo & 30 & 8 & 26,66 \\
\hline TOTAL & & $\mathbf{5 5 3}$ & 203 & 36,71 \\
\hline
\end{tabular}


CANDEIAS, J. A. N. \& RIBEIRO, L. C. - Anticorpos inibidores da hemaglutinacão para o vírus parainfluenza 3 (HA-1), em gado bovino. Rev. Saúde públ., S. Paulo, 2(2):180-185, dez. 1968.

investigação evidenciam uma ampla disseminação do vírus parainfluenza 3 no gado bovino examinado, considerando-se os resultados encontrados nos 19 Municípios de onde provieram as amostras examinadas. As porcentagens de positividade que encontramos são acentuadamente mais baixas do que as observadas pela grande maioria dos autores (ABINANTI et alii $^{3}$, 1961; Kramer et alii ${ }^{16}$, 1963; Cherby et alii $\left.{ }^{9}, 1967\right)$, o que poderá resultar, em parte, da utilização, como antígeno, de uma cêpa heteróloga. A êste respeito vale, no entanto, salientar que as observações de ABinanti et alii $^{2}$ (1960) e as de KeTLER et alii ${ }^{15}$ (1961), de que cobaias infectadas por via intranasal com uma só dose de vírus parainfluenza 3 produziam níveis de anticorpos inibidores da hemaglutinação, neutralizantes e fixadores de complemento maiores com o antígeno homólogo do que com o heterólogo, são válidas frente a uma dose única de antígeno. Se o antígeno homólogo era inoculado em doses múltiplas, perdia-se a especificidade da resposta antigênica, situação que muito se assemelha à de múltiplas infecções naturais capazes de levar a uma mais ampla capacidade de reação.

Fischman ${ }^{11}$ (1965) pesquisou anticorpos neutralizantes para o vírus parainfluenza 3 em carneiros, usando uma cêpa humana e uma cêpa bovina e encontrou $81 \%$ de soros positivos ( $\geq 1: 20)$; salienta o autor que êstes anticorpos estavam mais intimamente relacionados com a cêpa bovina do que com a cêpa humana. O mesmo autor em trabalho posterior (Fischman ${ }^{13}, 1967$ ) referente a um estudo epidemiológico em carneiros e suínos, utiliza, como antígenos, uma cêpa humana e uma cêpa bovina e analisa os resultados sem maiores considerações sôbre a especificidade das reações obtidas em função dos antígenos usados. ST. GeORGE \& French ${ }^{20}$ (1966) referem-se ao isolamento, de bovinos, de uma nova cêpa de vírus parainfluenza (PZL) soro. lògicamente relacionada com a cêpa humana PI3; ao mesmo tempo, comentam o en- contro de anticorpos neutralizantes, para a cêpa humana, de vírus parainfluenza 3 , num estudo com soros de bovinos, na Austrália. Chanock, Bell \& Parrott ${ }^{6}$ (1960), estudando casos de infecção primária e reinfecção pelo vírus parainfluenza 3 , em crianças, puderam observar alguns soros humanos reagindo igualmente frente à cêpa humana e bovina, enquanto noutros não pôde observar-se a presença de anticorpos heterólogos. Observaçôes desta natureza dão ao problema das relaçôes antigênicas entre as cêpas humana $\mathrm{e}$ bovina um interêsse muito particular $e$ sugerem a possibilidade do uso da cêpa heteróloga em inquéritos de natureza epidemiológica, principalmente, se levarmos em consideração as observações de FisCHMAN \& BANG ${ }^{12}$ (1966), segundo as quais as relações antigênicas cruzadas manifestam-se em um só sentido.

As porcentagens de positividade menos elevadas, encontradas por nós, poderão ainda ser atribuídas e talvez com mais razão ao tratamento dos soros pelo caolin, para destruição dos inibidores inespecíficos, cuja presença pode falsear os resultados da reação de inibição da hemaglutinação. KETLER, HAMPARIAM \& Hilleman ${ }^{15}$ (1961), baseados em dados experimentais, consideram que a presença dêstes inibidores não afeta os resultados das pesquisas serodiagnósticas e seroepidemiológicas, sendo desnecessário aquêle tratamento. Pareceu-nos mais indicado seguir o critério de acôrdo com o qual deve correr-se o risco da destruiçáo do anticorpo em soros de títulos baixos, frente à possibilidade de existirem inibidores capazes de dar falsos resultados positivos (Schmidt, LennetTe \& King ${ }^{13}, 1966$ ).

Sem deixar de considerar que os resultados obtidos no presente trabalho devem representar, em certa medida, um índice de infecção dos animais estudados, pelo vírus parainfluenza 3 , iniciamos nôvo inquérito sorológico em bovinos provenien. tes de 50 Municípios do Estado de São Paulo, usando um antígeno de origem bovina (Candeias \& Ribeiro ${ }^{5}, 1968$ ). 
CANDEIAS, J. A. N. \& RIBEIRO, L. C. - Anticorpos inibidores da hemaglutinação para o virus parainfluenza 3 (HA-1), em gado bovino. Rev. Saude públ., S. Paulo, 2(2):180-185, dez. 1968.

S U M M A R Y

A serological investigation in bovines from 19 Counties in the State of São Paulo, Brazil, evidence that $36.71 \%$ of the animals studied had haemagglutination-inhibiting antibodies for myxovirus parainfluenza 3 (HA-1). This result is an indication of dissemination of the in. fection caused by this virus, although an heterologous strain was used for detecting the above mentioned antibodies.

\section{REFERENCIAS BIBLIOGRAFICAS}

1. ABINANTI, F. R. \& HUEBNER, R. J. The serological relationship of strains of parainfluenza 3 virus isolated from humans and cattle with respiratory disease. Virology, 8(3):391-394, Jul., 1959.

2. ABINANTI, F. R. et alli - Relationship of human and bovine strains of myxovirus parainfluenza 3. Proc. Soc. exp. Biol, New York, 106(2):466-469, Feb. 1960.

3. ABINANTI, F. R. et alii - Serologic studies of myxovirus parainfluenza 3 in cattle and prevalence of antibodies in bovine. J. Immunol., 86(4):505-511, Apr., 1961.

4. AMERICAN PUBLIC HEALTH ASSOCIATION - Diagnostic procedure for viral and rickettsial diseases. 3rd ed. New York, 1964.

5. CANDEIAS, J. A. N. \& RIBEIRO, C. L - Inquérito sorológico em gado bovino do Estado de São Paulo: anticorpos inibidores da hemaglutinação para o virus parainfluenza 3 . (Em vias de publicacão.)

6. CHANOCK, R. M.; BELL, J. A. \& PARROTT, R. H. - Natural history of parainfluenza infection. In: Symposium on perspectives in Virology, 2nd, 1960. New York, 1960. p. 126.

7. CHANOCK, R. M, et alli - Association of hemadsorption viruses with respiratory illness in childhood. J.A.M.A., 169 (5) :548-533, Feb., 1958.

8. CHARTON, A. et alii - Etude préliminaire d'un virus hemadsorbant hémagglutinant isolé d'une lésion de pneumonie de veau. Bull. Acad. Vet. France, 38(5) :195-199, Mai, 1965.
9. CHERBY, J. et alii - Serological survey on cattle in France: haemagglutination-inhibiting antibodies due to myxovirus parainfluenza 3. Recl. Med. Vet., 143:755-765, 1967. Res. in Vet. Bull., 38 (5) :310, May, 1968.

10. COOK, M. D. et alii - Antigenic relationship among the newer myxoviruses. (parainfluenza). Amer, J. Hyg., 69(3): 250-264, May, 1959.

11. FISCHMAN, H. R. - Presence of neutralizing antibody for myxovirus parainfluenza 3 in sheep sera. Proc. Soc. exp. Biol., New York, 118(3):725-727, Mar., 1965.

12. FISCHMAN, H. R. \& BANG, F. B. Antigenic relationship of the human and bovine parainfluenza 3 viruses using the Ouchterlony technique. Proc. Soc. exp. Biol., Ne'w York, 121(3):966-970, Mar., 1966.

13. FISCHMAN, H. R. - Epidemiology of parainfluenza 3 infection in sheep. A mer. J. Epid., 85(2):272-281, Mar., 1967.

14. HOERLEIN, A. B. et alii - Studies of shipping fever of cattle. I. Parainfluenza 3 virus antibodies in feeder calves. J. A. V. M. A.,135(1):153-160, Aug., 1959.

15. KETLER, A.; HAMPARIAN, V. V. \& HILLEMAN, M. R. - Laboratory and field investigations of bovine myxovirus parainfluenza 3 virus and vaccine: $I$. Properties of the SF-4 (shipping fever) strain of virus. J. Immunol., $87(2): 126$ -133, Aug., 1961.

16. KRAMER, L. L. et alii - Epizootiology of bovine myxovirus parainfluenza 3 (SF-4) in Nebraska cattle as determined by antibody titers. J.A.V.M.A., 142(4): 375-378, Feb., 1963.

17. REISINGER, R. C.; HEDDLESTON, K. L. \& MANTHEI, C. A. - A myxovirus (SF-4) associated with shipping fever of cattle. J.A.V.M.A. $\quad 135(1): 147-152$, Aug., 1959.

18. SCHMIDT, N. J.; LENNETTE, E. H. \& KING, C. J. - Neutralizing hemagglutination-inhibiting and group complement-fixing antibody response in human adenovirus infection. J. Immunol., 97(1): 64-74, Jul., 1966. 
CANDEIAS, J. A. N. \& RIBEIRO, L. C. - Anticorpos inibidores da hemaglutinacão para o vírus parainfluenza 3 (HA-1), em gado bovino. Rev. Saúde públ., S. Paulo, 2(2):180-185, dez. 1968.

19. SEVER, J. L. - Application of a microtechnique to viral serological investions. J. Immunol., 88(3):320-329, Mar., 1962.

20. ST. GEORGE, T. D. \& FRENCH, E. L. Isolation of a bovine strain of myxovirus parainfluenza type 3 in Australia. Austr. Vet. J., 42(11): 438-439, Nov., 1966.
21. TAKATSY, G. apud SEVER, J, L. et alii - Serological diagnosis "en masse" with multiple antigens. Amer. J, resp. Dis., 88(3):342-359, Sept., 1963.

22. WOODS, G. et alii - Isolation and transmission studies with bovine parainfluenza 3 virus. Amer. J. Vet. Res., 25(6): 1021-1026, Dec., 1964. 